\title{
Survival outcomes and progonostic factors of extrahepatic cholangiocarcinoma patients following surgical resection: Adjuvant therapy is a favorable prognostic factor
}

\author{
HAIXIA YANG ${ }^{1}$, JIUPENG ZHOU $^{2}$, XIN WEI $^{1}$, FAN WANG $^{3}$, HUADONG ZHAO $^{4}$ and ENXIAO LI ${ }^{1}$ \\ ${ }^{1}$ Department of Medical Oncology, First Affiliated Hospital of Xi'an Jiaotong University, Xi'an, Shaanxi 710061; \\ ${ }^{2}$ Department of Medical Oncology, Sengong Hospital of Shaanxi, Xi'an, Shaanxi 710300; ${ }^{3}$ Department of Pediatrics, \\ First Affiliated Hospital of Xi'an Jiaotong University, Xi'an, Shaanxi 710061; ${ }^{4}$ Department of \\ General Surgery, Tangdu Hospital, Xi'an, Shaanxi 710038, P.R. China
}

Received June 4, 2014; Accepted July 29, 2014

DOI: $10.3892 / \operatorname{mco} .2014 .377$

\begin{abstract}
This study was conducted to investigate survival and prognostic factors for extrahepatic cholangiocarcinoma (ECC) following surgical resection and evaluate the effects of postoperative adjuvant therapy (AT) on overall survival (OS). We retrospectively collected clinical and pathological data between March, 2008 and December, 2013. The Kaplan-Meier method and the COX regression model were used to evaluate the OS and prognostic factors of 105 postoperative ECC patients, of whom 32 had received AT. The patients were stratified into seven risk subgroups and the survival rates were compared within each subgroup between patients who received AT and those who did not. The results demonstrated a median OS of 17.6 months, with 1- and 3-year survival rates of 67.9 and $19.5 \%$, respectively, for the entire cohort. On univariate analysis, preoperative cholangitis, non-R0 surgical margins, poor differentiation grade, stage $3 / 4$ and lymphatic metastasis were identified as adverse prognostic factors. AT was not significantly associated with improved OS. However, the subgroup analysis revealed that the effect of AT was significant only in the lymphatic metastasis group (median OS, 21.6 vs. 10.4 months; and 3-year OS, 16.6 vs. $0 \%$, respectively; $\mathrm{P}=0.02$ ). The survival curves of the AT and non-AT groups were significantly different only for node-positive patients. The COX regression model identified lymphatic metastasis, surgical margins and AT as independent prognostic factors for ECC. A negative resection margin may reduce the mortality
\end{abstract}

Correspondence to: Dr Enxiao Li or Dr Haixia Yang, Department of Medical Oncology, First Affiliated Hospital of Xi'an Jiaotong University, 277 Yanta West Road, Xi'an, Shaanxi 710061, P.R. China

E-mail: doclienxiao@sina.com

E-mail: yhx2015111@163.com

Key words: adjuvant therapy, extrahepatic cholangiocarcinoma, prognosis, survival rate following surgery by $47 \%$. By contrast, lymph node metastasis was associated with a 2.18 -fold higher mortality rate for ECC patients. Postoperative AT contributed to a 0.45 -fold mortality rate compared to non-AT ECC patients. Therefore, we concluded that AT is a favorable prognostic factor for ECC patients and it may prolong the survival of patients with lymphatic metastasis. Our data suggest that postoperative AT should be recommended for node-positive ECC patients.

\section{Introduction}

Extrahepatic cholangiocarcinoma (ECC) is a relatively rare malignant tumor of the bile duct epithelium, with a significantly increasing incidence among women (1). ECC is classified into two types according to anatomical location, namely perihilar and distal types, but does not include the papilla of Vater. Currently, complete surgical resection is the only curative option for ECC patients. However, the resectability rate of ECC cases has been low, as the majority of the patients have advanced-stage disease at diagnosis (2). Even following complete resection, the majority of the patients develop local recurrence or distant metastasis (3). The low overall survival (OS) rate of ECC $(4,5)$ is considered an oncologic challenge.

The number of studies on survival outcomes and prognostic factors of ECC patients following resection is limited and the results vary among different countries (5-year survival rate range, 16-54\%), with a median survival time range of 13-47.2 months (6-9). A variety of factors have been used to predict prognosis following surgical resection for ECC, but no consensus has been reached. Although postoperative adjuvant therapy (AT), including chemotherapy, radiotherapy, concurrent chemoradiotherapy and sequential chemotherapy and radiotherapy, have improved the disease-free survival and OS of patients in various other malignancies, the effects of AT on the survival in ECC patients have not yet been determined (10). The reasons may be as follows: Owing to the rarity of ECC, it usually takes several decades to collect the available data in most studies (11). Furthermore, it is generally considered that traditional cytotoxic chemotherapeutic drugs and radiotherapy are ineffective in ECC patients $(4,12,13)$. In addition, previous 
studies evaluated cholangiocarcinoma together with cancer of the gallbladder and the ampulla of Vater, due to the low incidence of ECC (14). Therefore, the role of AT in patients who underwent radical resection of ECC has not been clearly determined.

Therefore, this study aimed to investigate survival outcomes and prognostic factors of ECC patients following surgical treatment and determine the role of postoperative AT through a comparison of survival outcomes between ECC patients with and those without postoperative AT.

\section{Materials and methods}

Eligibility criteria. The eligibility criteria for the present study were as follows: patients with histologically proven ECC, without distant metastasis at diagnosis and without a history of malignancy other than skin cancer. Patients who had received preoperative chemotherapy and those with intrahepatic cholangiocarcinoma (ICC) and/or ampullary carcinoma were excluded from the study. Concurrent clinical and pathological data were retrospectively collected from 105 patients who underwent surgical resection of pathologically confirmed ECC between March 3, 2008 and December 20, 2013 at the First Affiliated Hospital of Xi'an Jiaotong University and the Tangdu Hospital. Demographic data were collected for each patient, including age, gender, imaging findings, laboratory test results and pathological results. The study was approved by the Ethics Committees of the two participating hospitals in March, 2008 and all the patients signed an informed consent.

Pathological evaluation. All the resected specimens were examined pathologically for tumor size, histological differentiation and the presence of positive lymph nodes. The surgical margins were examined for the presence of residual tumor, which was described by the residual tumor (R) classification as follows: R0, no residual tumor and resection margin $>0 \mathrm{~mm}$; $\mathrm{R} 1$, microscopic residual tumor or nil resection margin; and R2, macroscopic residual tumor (15). Each patient was staged according to the 7th edition of the American Joint Committee on Cancer (AJCC) staging system for ECC (16).

Preoperative cholangitis. Cholangitis was defined according to the international consensus-revised Tokyo Guidelines (17) and it was diagnosed when one of the three following conditions was present: i) purulent bile; ii) clinical remission following bile duct drainage; or iii) remission achieved by antibacterial therapy alone in patients in whom the only site of infection was the biliary tree.

$A T$. AT was administered in 32 ECC patients undergoing surgical resection. A total of 18 patients received systematic intravenous chemotherapy and each patient completed at least 2 cycles of chemotherapy. All the regimens of intravenous chemotherapy in our study were combinations of chemotherapeutic agents $(n=18)$, including gemcitabine/cisplatin $(n=8)$, gemcitabine/oxaliplatin $(n=6)$ and gemcitabine/capecitabine $(n=4)$. As regards postoperative adjuvant radiotherapy, 11 patients received three-dimensional conformal radiotherapy after surgical resection, with a total dose of 45-50 Gy, in 5 fractions per week, with 1.8 Gy per fraction, including the primary tumor bed as well as the regional lymph nodes. In addition, 2 patients were administered postoperative radiotherapy with a total dose of $45 \mathrm{~Gy}$, followed by single-agent capecitabine orally, $650 \mathrm{mg} / \mathrm{m}^{2}$ on days $1-14 \mathrm{q} 3 \mathrm{w} \times 4$ cycles and 1 patient received concurrent chemoradiotherapy, with a total dose of 45 Gy and 5-fluorouracil (5-FU) plus leucovorin as radiosensitizers.

Follow-up. After surgery, all the patients were regularly followed up by ultrasound scan, liver function tests and measurement of carbohydrate antigen 19-9 (CA19-9) at 1- to 3-month intervals. Survival time was calculated from the date of surgery. The patients were followed up until death or until the study deadline date, which was December 10, 2013. By the end of the study, 75 patients $(71.4 \%)$ had succumbed to the disease.

Statistical analysis. OS rates were calculated with the Kaplan-Meier method. The possible prognostic factors were analyzed by univariate analysis and evaluated using the Kaplan-Meier method; differences in survival curves were compared with the log-rank test. The baseline characteristics were compared between patients who received AT and those who did not using the Chi-square test. The multivariate analysis was performed using the Cox proportional hazards model to identify the independent prognostic factors for survival. Statistical analysis was performed using the SPSS 18.0 software for windows (SPSS, Inc., Chicago, IL, USA). P<0.05 was considered to indicate statistically significant differences.

\section{Results}

Demographics and clinicopathological characteristics of ECC patients. A total of 105 postoperative ECC patients were included in this study. The patients had a mean age of 62 years and included 50 men and 55 women. A common underlying liver disease in these patients was cholangitis $(22 / 105,20.95 \%)$. Elevated CA19-9 levels were detected in $65.71 \%(69 / 105)$ and lymph node metastasis in $38.1 \%$ (40/105) of the patients. According to the 7th edition of the AJCC staging system, $68.57 \%(72 / 105)$ of the patients had stage $1 / 2$ and $31.43 \%$ $(33 / 105)$ had stage $3 / 4$ disease. The R0 resectability rate was $59.05 \%(62 / 105)$. AT was administered to $30.5 \%(32 / 105)$ of the patients after surgery in this series.

Univariate analysis of survival rates, survival time and prognostic factors. At a median follow-up of 15.4 months, the median OS time was 17.6 months, with 1- and 3-year survival rates of 67.9 and $19.5 \%$, respectively, for the entire cohort, with corresponding rates of 52.3 and $7.3 \%$ for the patients with lymphatic metastasis; 76.5 and $26.1 \%$ for the patients without lymphatic metastasis $(\mathrm{P}=0.003) ; 44.8$ and $13.6 \%$ for the surgical margin-positive patients; and 83.2 and $22.4 \%$ for surgical margin-negative patients $(\mathrm{P}=0.003)$, respectively (Table I).

The univariate analysis (Table I) identified the following adverse prognostic factors for OS: preoperative cholangitis [hazard ratio $(\mathrm{HR})=1.70, \mathrm{P}=0.047$ ]; non-R0 surgical margins $(\mathrm{HR}=1.97, \mathrm{P}=0.003)$, poor differentiation grade $(\mathrm{HR}=1.70$, $\mathrm{P}=0.02)$, stage $3 / 4(\mathrm{HR}=3.47, \mathrm{P}<0.01)$ and lymphatic metastasis 
Table I. Univariate analysis of overall survival following resection for ECC $(n=105)$.

\begin{tabular}{|c|c|c|c|c|c|c|c|}
\hline \multirow[b]{2}{*}{ Clinical factors } & \multirow[b]{2}{*}{ No. } & \multicolumn{2}{|c|}{ Survival rate $(\%)$} & \multirow{2}{*}{$\begin{array}{l}\text { Median survival } \\
\text { (months) }\end{array}$} & \multirow{2}{*}{$\begin{array}{c}\text { P-value } \\
(\log -\text { rank })\end{array}$} & \multirow[b]{2}{*}{ HR } & \multirow{2}{*}{$\begin{array}{c}95 \% \mathrm{CI} \\
\text { for } \operatorname{Exp}(\mathrm{B})\end{array}$} \\
\hline & & 1-year & 3-year & & & & \\
\hline \multicolumn{8}{|l|}{ Gender } \\
\hline Male & 50 & 60.4 & 16.6 & 17.2 & 0.79 & 0.94 & $0.60-1.48$ \\
\hline Female & 55 & 74.1 & 22.4 & 18.8 & & & \\
\hline \multicolumn{8}{|c|}{ Age at surgery (years) } \\
\hline$\leq 70$ & 80 & 64.3 & 17.7 & 17.2 & 0.13 & 0.65 & $0.37-1.15$ \\
\hline$>70$ & 25 & 79.3 & 17.8 & 24.6 & & & \\
\hline \multicolumn{8}{|c|}{ Preoperative cholangitis } \\
\hline Yes & 22 & 59.9 & 8.2 & 12.3 & $0.047^{\mathrm{a}}$ & 1.70 & $1.00-2.90$ \\
\hline No & 83 & 70.0 & 23.5 & 20.2 & & & \\
\hline \multicolumn{8}{|l|}{ CA19-9 (U/ml) } \\
\hline$\leq 39$ & 36 & 76.9 & 25.2 & 23.0 & 0.23 & 1.35 & $0.82-2.21$ \\
\hline$>39$ & 69 & 61.6 & 16.5 & 15.9 & & & \\
\hline \multicolumn{8}{|c|}{ Lymphatic metastasis } \\
\hline Yes & 40 & 52.3 & 7.3 & 13.8 & $0.003^{\mathrm{a}}$ & 1.98 & $1.24-3.17$ \\
\hline No & 65 & 76.5 & 26.1 & 20.2 & & & \\
\hline \multicolumn{8}{|l|}{ Surgical margins } \\
\hline $\mathrm{R} 0^{\mathrm{b}}$ & 62 & 83.2 & 22.4 & 23.8 & $0.003^{\mathrm{a}}$ & 1.97 & $1.25-3.12$ \\
\hline Non-R0 & 43 & 44.8 & 13.6 & 11.6 & & & \\
\hline \multicolumn{8}{|l|}{ Child-Pugh class } \\
\hline A & 54 & 65.3 & 15.8 & 17.6 & 0.39 & 0.82 & $0.52-1.29$ \\
\hline $\mathrm{B}$ & 51 & 70.6 & 23.2 & 18.1 & & & \\
\hline \multicolumn{8}{|l|}{ Adjuvant therapy } \\
\hline Yes & 32 & 78.6. & 19.3 & 21.6 & 0.57 & 0.87 & $0.52-1.44$ \\
\hline No & 73 & 62.0 & 18.3 & 15.9 & & & \\
\hline \multicolumn{8}{|c|}{ Histological grade } \\
\hline $1 / 2$ & 68 & 74.8 & 22.7 & 21.6 & $0.02^{\mathrm{a}}$ & 1.70 & $1.07-2.72$ \\
\hline 3 & 37 & 55.4 & 14.6 & 12.3 & & & \\
\hline \multicolumn{8}{|l|}{ AJCC stage } \\
\hline $1 / 2$ & 72 & 80.0 & 28.4 & 24.0 & $<0.01^{\mathrm{a}}$ & 3.47 & $2.11-5.71$ \\
\hline $3 / 4$ & 33 & 39.6 & 0 & 11.5 & & & \\
\hline All patients & 105 & 67.9 & 19.5 & 17.6 & & & \\
\hline
\end{tabular}

${ }^{\mathrm{a}} \mathrm{P}<0.05$. ${ }^{\mathrm{N}} \mathrm{No}$ residual tumor and resection margin $>0 \mathrm{~mm}$. ECC, extrahepatic cholangiocarcinoma; HR, hazard ratio; CI, confidence interval; CA19-9, carbohydrate antigen 19-9; AJCC, American Joint Committee on Cancer.

$(\mathrm{HR}=1.98, \mathrm{P}=0.003)$. The univariate analysis demonstrated that AT was not significantly associated with improved OS $(\mathrm{HR}=0.87, \mathrm{P}=0.57)$. The survival curves were not significantly different between the AT and non-AT groups for the entire cohort of patients (Fig. 1).

Baseline characteristics of patient demographics and tumor characteristics between AT and non-AT groups. We used Chi-square tests for the categorical comparisons of patient baseline characteristics between the AT and non-AT groups (Table II). Significant differences were found in baseline characteristics between the two groups. The patients who received AT $(n=32)$ were younger compared to the non-AT patients $(n=73)(90.6$ vs. $69.9 \%$, respectively, were aged $<70$ years; $\mathrm{P}=0.02)$. In addition, the patients who received AT exhibited a higher rate of stage $3 / 4$ disease ( 46.9 vs. $24.7 \%$, respectively; $\mathrm{P}=0.02)$, lymphatic metastasis (62.5 vs. $27.4 \%$, respectively; $\mathrm{P}=0.001$ ) and positive resection margins (56.3 vs. $34.2 \%$, respectively; $\mathrm{P}=0.035$ ). As a result, the survival outcomes between the two groups cannot be directly compared due to the significantly different baseline characteristics.

Subgroup survival analysis by the Kaplan-Meier method. The patients were stratified into seven risk subgroups according to clinical factors and the survival rate was compared within each subgroup between patients who received AT and those 
Table II. Comparison of baseline characteristics between treatment groups with the Chi-square test.

\begin{tabular}{|c|c|c|c|}
\hline Clinical factors & $\begin{array}{c}\text { Non-AT } \\
\mathrm{n}=73(\%)\end{array}$ & $\begin{array}{c}\text { AT } \\
\mathrm{n}=32(\%)\end{array}$ & P-value \\
\hline \multicolumn{4}{|c|}{ Age at surgery (years) } \\
\hline$<70$ & $51(69.9)$ & $29(90.6)$ & $0.02^{\mathrm{a}}$ \\
\hline$\geq 70$ & $22(30.1)$ & $3(9.4)$ & \\
\hline \multicolumn{4}{|l|}{ Gender } \\
\hline Male no. & $39(53.4)$ & $11(34.4)$ & 0.07 \\
\hline \multicolumn{4}{|c|}{ Tumor characteristics } \\
\hline \multicolumn{4}{|l|}{ T stage } \\
\hline $1 / 2$ & $55(75.3)$ & $17(53.1)$ & $0.02^{\mathrm{a}}$ \\
\hline $3 / 4$ & $18(24.7)$ & $15(46.9)$ & \\
\hline \multicolumn{4}{|c|}{ Lymphatic metastasis } \\
\hline No & $53(72.6)$ & $12(37.5)$ & $0.001^{\mathrm{a}}$ \\
\hline Yes & $20(27.4)$ & $20(62.5)$ & \\
\hline \multicolumn{4}{|l|}{ Histology grade } \\
\hline $1 / 2$ & $48(65.7)$ & $20(62.5)$ & 0.75 \\
\hline 3 & $25(34.3)$ & $12(37.5)$ & \\
\hline \multicolumn{4}{|l|}{ Surgical margins } \\
\hline Non-R0 & $25(34.2)$ & $18(56.3)$ & $0.035^{\mathrm{a}}$ \\
\hline R0 & $48(65.8)$ & $14(43.7)$ & \\
\hline \multicolumn{4}{|c|}{ Preoperative cholangitis } \\
\hline Yes & $14(19.2)$ & $8(25.0)$ & 0.50 \\
\hline No & $59(80.8)$ & $24(75.0)$ & \\
\hline
\end{tabular}

${ }^{\mathrm{a}} \mathrm{P}<0.05$. ${ }^{\mathrm{b}} \mathrm{No}$ residual tumor and resection margin $>0 \mathrm{~mm}$. AT, adjuvant therapy.

who did not. Only patients with pathological lymphatic metastasis exhibited a significant difference in the 3-year survival rate between the AT and non-AT groups (median OS, 21.6 vs. 10.4 months; and 3-year OS, 16.6 vs. $0 \%$, respectively; $\mathrm{P}=0.02$ ) (Table III). The survival curves of the AT and non-AT groups for node-positive patients were significantly different (Fig. 2). The remaining patients did not achieve a significant improvement in OS with AT $(\mathrm{P}>0.05)$ (Table III).

Multivariate analysis of prognostic factors. The prognostic factors considered significant on univariate analysis were subjected to multivariate analysis using a Cox proportional hazards model. These factors included surgical margins, lymphatic metastasis, histological grade, preoperative cholangitis and AT. Our data demonstrated that lymph node metastasis $(\mathrm{HR}=2.185, \mathrm{P}=0.009)$, surgical margin positivity $(\mathrm{HR}=1.893, \mathrm{P}=0.015)$ and $\mathrm{AT}(\mathrm{HR}=0.451, \mathrm{P}=0.011)$ remained independently associated with OS (Table IV).

\section{Discussion}

The documentation of ECC outcomes is sparse and its prognosis remains unsatisfactory, even after radical surgical resection. The overall 1- and 3-year survival rates in our series were consistent with previous findings (5). The median survival

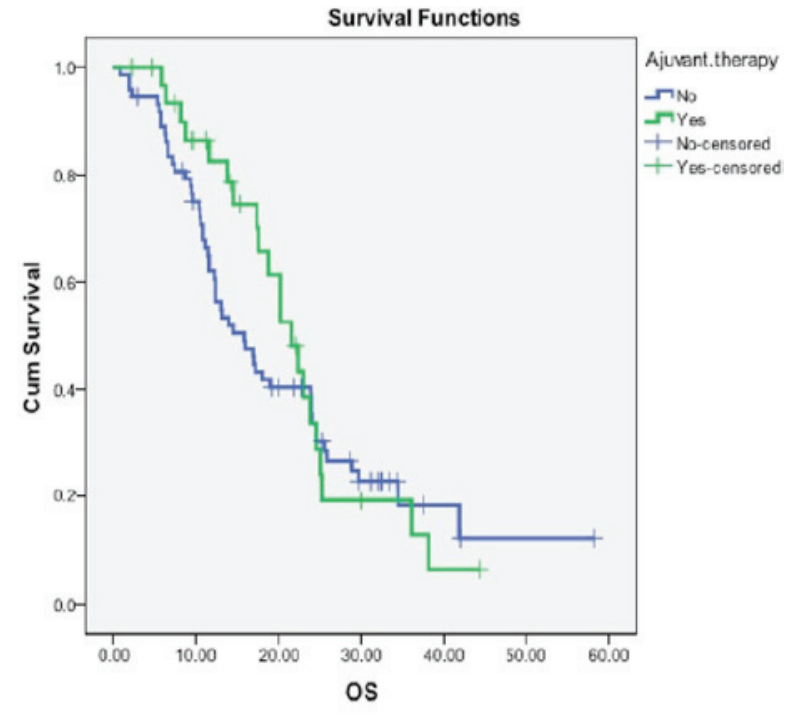

Figure 1. Overall survival (OS) rate of 105 extrahepatic cholangiocarcinoma patients after surgery according to administration of adjuvant therapy (AT). The survival curves were not significantly different between the AT and non-AT groups for the entire cohort of patients.

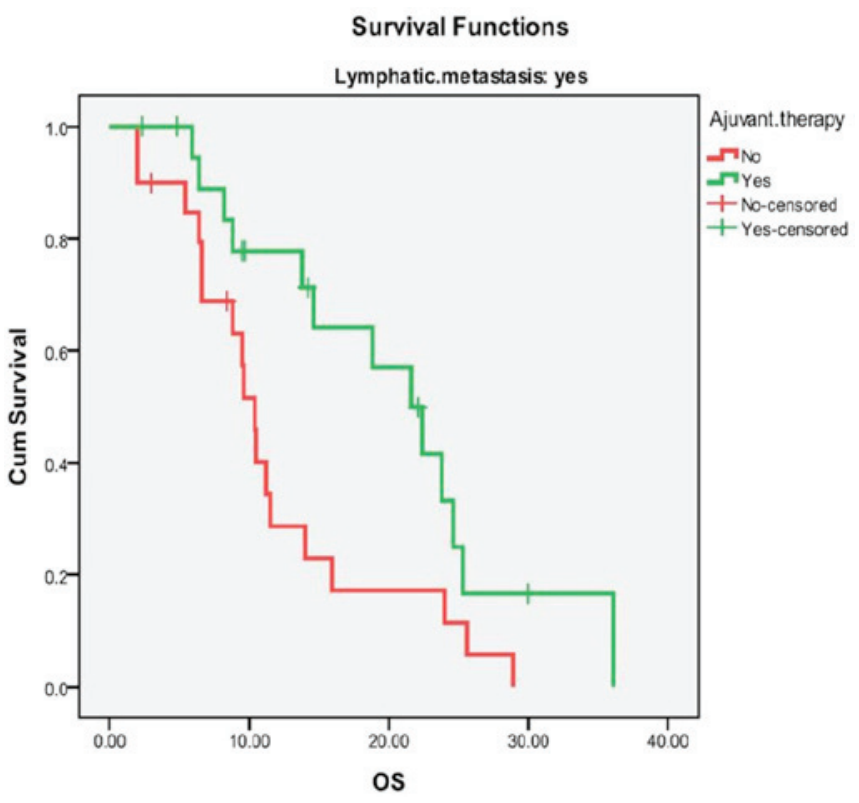

Figure 2. Kaplan-Meier method comparing overall survival (OS) in patients with lymphatic metastasis between patients who received adjuvant therapy (AT) $(n=20)$ and those treated without AT $(n=20)$. The survival curves of AT and non-AT groups for node-positive patients were significantly different.

time in this study (17.6 months) is quite similar to the median survival time of 17 months reported by Fuller et al (18). However, our results differ from the higher survival rates reported by previous studies (19-21). These differences may be attributed to patient demographics and tumor characteristics, duration of follow-up and treatment modalities. In addition, there was a considerable number of ECC patients with positive lymph nodes $(40 / 105,38.1 \%)$, residual margins $(43 / 105$, $40.96 \%)$, preoperative cholangitis $(22 / 105,20.95 \%)$, poor histological differentiation $(37 / 105,35.24 \%)$ and stage $3 / 4$ disease $(33 / 105,31.43 \%)$ in our study, which were adverse prognostic 
Table III. Subgroup survival analysis comparing patients who received AT to those who did not using the Kaplan-Meier method.

\begin{tabular}{|c|c|c|c|c|c|c|c|}
\hline \multirow[b]{2}{*}{ Clinical factors } & \multicolumn{2}{|c|}{ No. of patients } & \multicolumn{3}{|c|}{ Median overall survival (months) } & \multicolumn{2}{|c|}{ 3-year survival (\%) } \\
\hline & Non-AT & AT & Non-AT & AT & P-value & Non-AT & AT \\
\hline All patients (\%) & $73(69.5)$ & $32(30.5)$ & 15.9 & 21.6 & 0.57 & 18.3 & 19.3 \\
\hline \multicolumn{8}{|l|}{ Age (years) } \\
\hline$\leq 70$ & 51 & 29 & 12.3 & 21.6 & 0.23 & 15.3 & 21.2 \\
\hline$>70$ & 22 & 3 & 24.6 & 25.1 & 0.57 & 19.7 & 33.3 \\
\hline \multicolumn{8}{|l|}{ Gender } \\
\hline Female & 34 & 21 & 15.9 & 22.4 & 0.76 & 22.3 & 20.8 \\
\hline Male & 39 & 11 & 13.1 & 20.2 & 0.63 & 15.8 & 14.8 \\
\hline \multicolumn{8}{|l|}{ Histological grade } \\
\hline $1 / 2$ & 48 & 20 & 17.0 & 23.8 & 0.30 & 21.7 & 24.2 \\
\hline 3 & 25 & 12 & 12.3 & 14.6 & 0.93 & 0 & 11.1 \\
\hline \multicolumn{8}{|c|}{ Lymphatic metastasis } \\
\hline No & 53 & 12 & 19.0 & 20.2 & 0.80 & 25.3 & 22.5 \\
\hline Yes & 20 & 20 & 10.4 & 21.6 & $0.02^{\mathrm{a}}$ & 0 & 16.6 \\
\hline \multicolumn{8}{|l|}{ AJCC stage } \\
\hline $1 / 2$ & 55 & 17 & 23.9 & 24.6 & 0.30 & 24.5 & 37.5 \\
\hline $3 / 4$ & 18 & 15 & 10.5 & 14.6 & 0.10 & 0 & 0 \\
\hline \multicolumn{8}{|l|}{ Surgical margins } \\
\hline R0 & 48 & 14 & 24.0 & 20.2 & 0.89 & 22.3 & 20.0 \\
\hline Non-R0 ${ }^{\mathrm{b}}$ & 25 & 18 & 9.6 & 22.4 & 0.07 & 8.9 & 18.6 \\
\hline \multicolumn{8}{|c|}{ Preoperative cholangitis } \\
\hline Yes & 14 & 8 & 12.3 & 12.8 & 0.5 & 0 & 14.3 \\
\hline No & 59 & 24 & 17.0 & 21.6 & 0.57 & 23.7 & 20.9 \\
\hline
\end{tabular}

${ }^{\mathrm{a}} \mathrm{P}<0.05$. ${ }^{\mathrm{b}}$ No residual tumor and resection margin $>0 \mathrm{~mm}$. AT, adjuvant therapy; AJCC, American Joint Committee on Cancer.

Table IV. Multivariate analysis of overall survival following surgical resection for ECC $(\mathrm{n}=105)$.

\begin{tabular}{|c|c|c|c|c|c|c|c|c|}
\hline \multirow[b]{2}{*}{ Clinical factors } & \multirow[b]{2}{*}{ B } & \multirow[b]{2}{*}{ SE } & \multirow[b]{2}{*}{ Wald } & \multirow[b]{2}{*}{ df } & \multirow[b]{2}{*}{ Sig. } & \multirow[b]{2}{*}{$\operatorname{Exp}(B)$} & \multicolumn{2}{|c|}{$95 \% \mathrm{CI}$ for $\operatorname{Exp}(\mathrm{B})$} \\
\hline & & & & & & & Lower & Upper \\
\hline Lymphatic metastasis & 0.782 & 0.300 & 6.814 & 1 & $0.009^{\mathrm{a}}$ & 2.185 & 1.215 & 3.931 \\
\hline Surgical margins & 0.638 & 0.263 & 5.889 & 1 & $0.015^{\mathrm{a}}$ & 1.893 & 1.131 & 3.171 \\
\hline Adjuvant therapy & -0.796 & 0.314 & 6.441 & 1 & $0.011^{\mathrm{a}}$ & 0.451 & 0.244 & 0.834 \\
\hline Histological grade & 0.039 & 0.274 & 0.020 & 1 & 0.887 & 1.040 & 0.607 & 1.781 \\
\hline Preoperative cholangitis & 0.425 & 0.294 & 2.098 & 1 & 0.147 & 1.530 & 0.861 & 2.720 \\
\hline
\end{tabular}

${ }^{\text {a }}<<0.05$. ECC, extrahepatic cholangiocarcinoma; CI, confidence interval; df, degree of freedom; sig., significance.

factors and may result in lower survival rates and a shorter median survival time.

The effect of preoperative inflammation on the prognosis of patients with ECC has not been extensively investigated (22). Previous findings verified that preoperative cholangitis in ECC patients was associated with a 2.2-fold higher mortality rate compared to that in patients without preoperative cholangitis (22). However, Liu et al (23) observed that the presence of inflammation was associated with improved postoperative survival in ICC patients. Luo et al (24) concluded that preoperative chronic proliferative cholangitis, possibly caused by hepatolithiasis, was unrelated to the OS of ICC. In our study, the univariate analysis identified preoperative cholangitis as a disadvantageous factor associated with the OS of ECC patients, while the multivariate analysis with a Cox proportional hazards model did not yield similar results. Further investigation on whether inflammation is a prognostic factor for ECC is required. 
The role of postoperative AT remains controversial for ECC (11). Several experts recommended postoperative adjuvant radiotherapy or chemotherapy for ECC patients, based mainly on institutional small-sampled evidence (11). However, the findings have been inconsistent. Certain retrospective studies reported a positive effect of adjuvant chemotherapy or radiotherapy on patients with resectable ECC $(19,25)$ whereas others reported no such effect $(4,26)$. In one randomized controlled trial investigating adjuvant chemotherapy for biliary carcinoma, Takada et al (14) reported the efficacy of adjuvant chemotherapy with mitomycin $\mathrm{C}$ and $5-\mathrm{FU}$ in gallbladder carcinoma, but not in bile duct carcinoma patients. Additionally, Pitt et al (27) reported no improvement in OS with adjuvant radiation in the only randomized controlled trial on postoperative adjuvant radiotherapy for perihilar cholangiocarcinoma. These two large-sampled controlled clinical trails demonstrated that neither adjuvant chemotherapy nor radiotherapy improved the survival of ECC patients. Thus far, the findings of AT have been quite discouraging for oncologists.

However, the high rates of relapse and metastasis following surgical resection have prompted further investigation of AT for 'high-risk' ECC, although the literature in this area remains sparse. The combined administration of gemcitabine and cisplatin has shown convincing efficacy regarding survival in advanced biliary tract carcinoma and has become a standard therapy (28). Consequently, certain investigators attempted to treat postoperative ECC patients using gemcitabine-based chemotherapeutic regimens. A systematic review and meta-analysis demonstrated beneficial effects of AT on cholangiocarcinoma patients, with significant prolongation of the OS in the lymphatic metastasis and surgical margin-positive subgroups (11). The latest results from several small-sampled retrospective studies indicated that gemcitabine-based chemotherapy may improve OS outcomes for ECC following surgical resection, as compared to the outcomes reported in previous studies (3,25,29-31). In addition, an open-label, phase 3 , randomized controlled trial investigating adjuvant chemotherapy for periampullary adenocarcinoma, including 297 cases of ampullary cancer, 96 cases of bile duct cancer and 35 cases of other cancers, reported that adjuvant chemotherapy was associated with significant survival benefits in the entire patient cohort $(\mathrm{HR}=0.75)$, although this effect requires further improvement (32).

Similarly, certain researchers treated ECC patients with radiotherapy following surgical resection. A bulk of retrospective data suggested that improved survival may be achieved with the use of adjuvant radiation following surgical treatment, particularly with dose escalation (10). In addition, previous studies reported that adjuvant concurrent chemoradiotherapy using three-dimensional conformal radiotherapy improved locoregional control and survival in ECC patients with $\mathrm{R} 1$ resection or positive lymph nodes (33-38). In the present study, postoperative AT did not appear to exert a positive effect on ECC patients as a whole. However, the survival time of node-positive ECC patients was significantly prolonged when compared to that of non-AT patients. Following adjustment for lymph node metastasis, histological type, surgical margins, preoperative cholangitis and stage, AT remained a statistically significant prognostic factor for postoperative survival. Postoperative AT contributed to a 0.45 -fold mortality rate compared to non-AT ECC patients.

There were certain limitations to this study. First, the study design was non-randomized and retrospective, which may be the source of uncontrolled bias. Second, the interval time of follow-up was not equally controlled for each patient; therefore, the relapse-free survival time of patients could not be presented. Additionally, the ATs involved in this study have not been separately analyzed due to the limited samples.

In conclusion, negative surgical margins and negative lymph node status, together with AT, were identified as independent favorable prognostic factors in ECC patients following surgical resection. Therefore, AT may prolong the OS of lymph node-positive EEC patients following surgical resection. The findings of the present study suggest that patients with node-positive disease may benefit from postoperative adjuvant chemotherapy or radiotherapy. However, a prospective clinical trial of AT in ECC is required to confirm these results.

\section{Acknowledgements}

This study was supported by the Natural Science Foundation of China (grant no. 81172169).

\section{References}

1. Castro FA, Koshiol J, Hsing AW and Devesa SS: Biliary tract cancer incidence in the United States-Demographic and temporal variations by anatomic site. Int J Cancer 133: 1664-1671, 2013.

2. Gwak HK, Kim WC, Kim HJ and Park JH: Extrahepatic bile duct cancers: surgery alone versus surgery plus postoperative radiation therapy. Int J Radiat Oncol Biol Phys 78: 194-198, 2010.

3. Murakami Y, Uemura K, Sudo T, et al: Adjuvant gemcitabine plus S-1 chemotherapy improves survival after aggressive surgical resection for advanced biliary carcinoma. Ann Surg 250: 950-956, 2009.

4. Aljiffry M, Walsh MJ and Molinari M: Advances in diagnosis, treatment and palliation of cholangiocarcinoma: 1990-2009. World J Gastroenterol 15: 4240-4262, 2009.

5. Pattanathien P, Khuntikeo N, Promthet S and Kamsa-Ard S: Survival rate of extrahepatic cholangiocarcinoma patients after surgical treatment in Thailand. Asian Pac J Cancer Prev 14: 321-324, 2013.

6. Nagorney DM, Donohue JH, Farnell MB, Schleck CD and Ilstrup DM: Outcomes after curative resections of cholangiocarcinoma. Arch Surg 128: 871-879, 1993.

7. Kim JW, Jo S, Moon HJ, Heo JS, Choi SH, Joh JW, Choi DW, Chung JC and Kim YI: Prognostic factors after major resection for distal extrahepatic cholangiocarcinoma. Korean J Gastroenterol 47: 144-152, 2006 (In Korean).

8. Woo SM, Ryu JK, Lee SH, et al: Recurrence and prognostic factors of ampullary carcinoma after radical resection: comparison with distal extrahepatic cholangiocarcinoma. Ann Surg Oncol 14: 3195-3201, 2007.

9. Unno M, Katayose Y, Rikiyama T, et al: Major hepatectomy for perihilar cholangiocarcinoma. J Hepatobiliary Pancreat Sci 17: 463-469, 2010.

10. Anderson $\mathrm{C}$ and Kim R: Adjuvant therapy for resected extrahepatic cholangiocarcinoma: a review of the literature and future directions. Cancer Treat Rev 35: 322-327, 2009.

11. Horgan AM, Amir E, Walter T and Knox JJ: Adjuvant therapy in the treatment of biliary tract cancer: a systematic review and meta-analysis. J Clin Oncol 30: 1934-1940, 2012.

12. Khan SA, Thomas HC, Davidson BR and Taylor-Robinson SD: Cholangiocarcinoma. Lancet 366: 1303-1314, 2005.

13. Shimoda M and Kubota K: Multi-disciplinary treatment for cholangiocellular carcinoma. World J Gastroenterol 13: 1500-1504, 2007. 
14. Takada T, Amano H, Yasuda H, et al: Is postoperative adjuvant chemotherapy useful for gallbladder carcinoma? A phase III multicenter prospective randomized controlled trial in patients with resected pancreaticobiliary carcinoma. Cancer 95: 1685-1695, 2002.

15. Sasaki R, Takeda Y, Funato O, Nitta H, Kawamura H, Uesugi N, Sugai T, Wakabayashi G and Ohkohchi N: Significance of ducta margin status in patients undergoing surgical resection for extrahepatic cholangiocarcinoma. World J Surg 9: 1788-1796, 2007.

16. Edge SB, Byrd DR, Compton CC, Fritz AG, Greene FL and Trotti A (eds): AJCC Cancer Staging Manual. 7th Edition. New York, Springer, pp66-71, 2010

17. Kiriyama S, Takada T, Strasberg SM, et al: Tokyo Guidelines Revision Committee: New diagnostic criteria and severity assessment of acute cholangitis in revised Tokyo Guidelines. J Hepatobiliary Pancreat Sci 19: 548-556, 2012.

18. Fuller CD, Wang SJ, Choi M, et al: Multimodality therapy for locoregional extrahepatic cholangiocarcinoma: a population-based analysis. Cancer 115: 5175-5183, 2009.

19. Cheng Q, Luo X, Zhang B, Jiang X, Yi B and Wu M: Predictive factors for prognosis of hilar cholangiocarcinoma: postresection radiotherapy improves survival. Eur J Surg Oncol 33: 202-207, 2007.

20. Khuntikeo N,Pugkhem A, Bhudhisawasdi V and Uttaravichien T: Major hepatic resection for hilar cholangiocarcinoma without preoperative biliary drainage. Asian Pac J Cancer Prev 9: 83-85, 2008.

21. Li H, Qin Y, Cui Y, Chen H, Hao X and Li Q: Analysis of the surgical outcome and prognostic factors for hilar cholangiocarcinoma: a Chinese experience. Dig Surg 28: 226-231, 2011.

22. Cho JY, Han HS, Yoon YS, et al: Preoperative cholangitis and metastatic lymph node have a negative impact on survival after resection of extrahepatic bile duct cancer. World J Surg 36: $1842-1847,2012$

23. Liu RQ, Shen SJ, Hu XF, Liu J, Chen LJ and Li XY: Prognosis of the intrahepatic cholangiocarcinoma after resection: hepatitis B virus infection and adjuvant chemotherapy are favorable prognosis factors. Cancer Cell Int 13: 99, 2013.

24. Luo X, Yuan L, Wang Y, Ge R, Sun Y and Wei G: Survival outcomes and prognostic factors of surgical therapy for all potentially resectable intrahepatic cholangiocarcinoma: a large single-center cohort study. J Gastrointest Surg 18: 562-572, 2014

25. Wirasorn K, Ngamprasertchai T, Khuntikeo N, et al: Adjuvant chemotherapy in resectable cholangiocarcinoma patients. J Gastroenterol Hepatol 28: 1885-1891, 2013

26. Vern-Gross TZ, Shivnani AT, Chen K, et al: Survival outcomes in resected extrahepatic cholangiocarcinoma: effect of adjuvant radiotherapy in a surveillance, epidemiology, and end results analysis. Int J Radiat Oncol Biol Phys 81: 189-198, 2011
27. Pitt HA, Nakeeb A, Abrams RA, Coleman J, Piantadosi S, Yeo CJ, Lillemore KD and Cameron JL: Perihilar cholangiocarcinoma. Postoperative radiotherapy does not improve survival. Ann Surg 221: 788-798, 1995.

28. Valle J, Wasan H, Palmer DH, et al; ABC-02 Trial Investigators: Cisplatin plus gemcitabine versus gemcitabine for biliary tract cancer. N Engl J Med 362: 1273-1281, 2010.

29. Murakami Y, Uemura K, Sudo T, et al: Gemcitabine-based adjuvant chemotherapy improves survival after aggressive surgery for hilar cholangiocarcinoma. J Gastrointest Surg 13: 1470-1479, 2009.

30. Murakami Y, Uemura K, Sudo T, et al: Adjuvant chemotherapy with gemcitabine and S-1 after surgical resection for advanced biliary carcinoma: outcomes and prognostic factors. J Hepatobiliary Pancreat Sci 19: 306-313, 2012

31. Yamanaka K, Hatano E, Kanai M, et al: A single-center analysis of the survival benefits of adjuvant gemcitabine chemotherapy for biliary tract cancer. Int J Clin Oncol 19: 485-489, 2014

32. Neoptolemos JP, Moore MJ, Cox TF, et al; European Study Group for Pancreatic Cancer: Effect of adjuvant chemotherapy with fluorouracil plus folinic acid or gemcitabine vs observation on survival in patients with resected periampullary adenocarcinoma: the ESPAC-3 periampullary cancer randomized trial. JAMA 308: 147-156, 2012.

33. Hughes MA, Frassica DA, Yeo CJ, et al: Adjuvant concurrent chemoradiation for adenocarcinoma of the distal common bile duct. Int J Radiat Oncol Biol Phys 68: 178-182, 2007.

34. Borghero Y, Crane CH, Szklaruk J, et al: Extrahepatic bile duct adenocarcinoma: patients at high-risk for local recurrence treated with surgery and adjuvant chemoradiation have an equivalent overall survival to patients with standard-risk treated with surgery alone. Ann Surg Oncol 15: 3147-3156, 2008.

35. Bonet Beltran M, Roth AD, Mentha G and Allal AS: Adjuvant radio-chemotherapy for extrahepatic biliary tract cancers. BMC Cancer 11: 267, 2011.

36. Narang AK, Miller RC, Hsu CC, et al: Evaluation of adjuvant chemoradiation therapy for ampullary adenocarcinoma: the Johns Hopkins Hospital-Mayo Clinic collaborative study. Radiat Oncol 6: 126, 2011

37. Park JH, Choi EK, Ahn SD, et al: Postoperative chemoradiotherapy for extrahepatic bile duct cancer. Int J Radiat Oncol Biol Phys 79: 696-704, 2011.

38. Habermehl D, Lindel K, Rieken S, et al: Chemoradiation in patients with unresectable extrahepatic and hilar cholangiocarcinoma or at high risk for disease recurrence after resection: Analysis of treatment efficacy and failure in patients receiving postoperative or primary chemoradiation. Strahlenther Onkol 188: 795-801, 2012. 